\title{
THE IMPORTANCE OF DIGITIZATION AND INNOVATIONS FOR SMALL AND MEDIUM-SIZED ENTERPRISES \\ Miroslav Fusko ${ }^{1}$, Luboslav Dulina ${ }^{2}$, Peter Bubeník ${ }^{3}$, Monika Bučková ${ }^{4}$, Marta Kasajová $^{5}$, Radovan Svitek $^{6}$
}

\begin{abstract}
The importance of new disrupting technologies and innovations is crucial for Small and Medium-Sized Enterprises (SMEs). SMEs are critical to large factories because, in many cases, they are their suppliers. Therefore, there is a need for digitization solutions, innovative approaches, and disruptive technologies in these factories. These areas significantly disrupt the usual processes in SMEs. SMEs thus have to deal with significant changes in their business in a relatively short time. The benefits of new approaches for SMEs are described in the second half of the article in the case study. This study deals with the possibility of using a software tool from previous research on the workplace for the production planning and logistics systems team in the selected Slovak factory. The paper itself focuses on the Slovak engineering industry, digitalization and innovations. The selected factory manufactures compressor technology. The factory did not hesitate to use the possibility of cooperation and verification of various functionalities. The cooperation aimed to analyze the current state of production of the selected product and the subsequent design of increasing productivity and economic efficiency concerning improving its internal conditions.
\end{abstract}

JEL Classification Numbers: L23, L52, L16, O14, DOI: https://doi.org/10.12955/peb.v2.252

Keywords: rationalization, digitization, industrial engineering, productivity, SMEs

\section{Introduction}

The engineering industry in Slovakia is one of the key pillars of the Slovak economy. It has a strong historical background and maintains its stable position in the Slovak industry as a whole. Factories operating in the Slovak industrial environment are aware that research, development, and innovation are key factors in the survival of a given factory, not only a concept that is applied globally. There is also increasing pressure to create conditions for research and development in parent companies and Small and Medium-Sized Enterprises (SMEs). Last but not least, factories are also aware of the importance of innovation - its implementation in their internal processes and the production of new innovative products. SMEs represent $99 \%$ of all businesses in the EU. The European Commission divides these companies into micro - up to 10 employees, small to 50 employees, and medium-sized - up to 250 employees. The definition of an SME is important for access to finance and EU support programs targeting specifically such enterprises. Small and medium-sized enterprises in Slovakia make up an even larger share of the total number of business entities, accounting for $99.9 \%$ of the total. These factories provide employment to almost three quarters $(74 \%)$ of the active workforce in the corporate economy and account for more than half $(55 \%)$ of the value-added. The year 2019 was also the last year of a successful decade for small and medium-sized enterprises, which was characterized by an increase in the performance of the SME sector. However, the year 2020 significantly disrupted the business of SMEs due to the COVID-19 pandemic. These two areas significantly disrupt the usual processes in factories, which have to address it (Commission_1, 2021), (SBA, monitoringmsp, 2019), (NARMSP, 2013).

\section{The need for cooperation and promotion of innovation}

Cooperation plays a significant role in knowledge creation and innovation. Innovation cooperation among factories forms a complex network of factories R\&D departments. (Qiu, Wang, \& Chen, 2019), (Yang, 2018). The intensification of innovations required a system approach, including at the macro

\footnotetext{
${ }^{1}$ University of Zilina, Faculty of Mechanical Engineering, Department of Industrial Engineering miroslav.fusko@fstroj.uniza.sk, ORCID:0000-0003-3444-7532

${ }^{2}$ University of Zilina, Faculty of Mechanical Engineering, Department of Industrial Engineering luboslav.dulina@fstroj.uniza.sk, ORCID: 0000-0002-5385-7476

${ }^{3}$ University of Zilina, Faculty of Mechanical Engineering, Department of Industrial Engineering peter.bubenik@fstroj.uniza.sk, ORCID: 0000-0001-7841-9328

${ }^{4}$ University of Zilina, Faculty of Mechanical Engineering, Department of Industrial Engineering monika.buckova@fstroj.uniza.sk, ORCID: 0000-0002-3745-3914

${ }^{5}$ University of Zilina, Faculty of Mechanical Engineering, Department of Industrial Engineering marta.kasajova@fstroj.uniza.sk, ORCID: 0000-0001-6102-3378

${ }^{6}$ University of Zilina, Faculty of Mechanical Engineering, Department of Industrial engineering radovan.svitek@fstroj.uniza.sk, ORCID: 0000-0002-4105-4035
} 
level, which resulted in national innovation systems (NIS). These systems are designed to support and ensure innovation processes, including creating favourable conditions for interacting with different actors like businesses, universities, science parks, scientific institutions, states. Each actor performs its role in NIS, contributingo the total innovation productivity (Kolomytseva \& Pavlovska, 2020). The ability of factories, countries, and communities to innovate is currently much more than just one of the economic parameters. This progressive approach is one of the parameters of the economic power and, at the same time, security of the country. Energy and food security must be a matter of course for countries. However, in today's digital and rapidly changing times, the ability to innovate and adapt quickly to the new is becoming a very important geopolitical parameter. This also follows from the activities of countries described as traditional "innovation leaders" such as Denmark, Finland, the Netherlands, Sweden, etc. Last but not least, developing countries are also striving to increase the innovation performance of their economies. It is clear that in the context of global shifts in production factors, the position of the Slovak Republic as a country competing largely with cheap labor, is unsustainable in the long run (SBA, monitoringmsp, 2020), (Borik, et al., 2019).

Science parks, R\&D organizations and universities are complex organizations where innovations and suitable technologies are developed for common factories and factories of the future too (Frances \& Palomar, 2019). Therefore, it is necessary to look for suitable strategies not only for sustainability but also for increasing the competitiveness of Slovak factories. This will ultimately have a positive effect on entire industries. It is an innovation that makes it possible to achieve technological change and initiate new economic and technological cycles in the long run. Countries that were able to identify and support promising innovations or technologies in time have ensured prosperity for themselves. Innovation improves the socioeconomic position of factories, regions and entire countries. Therefore, it is necessary to specifically support the innovative activities of factories, their groupings (clusters), and other entities' involvement in economic processes.

The measures in the manufacturing plants, which disrupt the COVID 19 business, will end once, so it is time for the factories to think about how they will continue to operate after the measures expire. In some cases, factories will have to continue with lower orders, while others may have to grow. All of this will ask how much real resources will be needed - not only people, but also machinery and equipment, materials, and, of course, the performance of support departments to ensure the smooth running of production. It will often be necessary to re-evaluate the balancing/balancing of lines to prepare variants. It will be necessary to react quickly to minimize the economic impact of the crisis caused by the pandemic. It is currently unclear how long the unfavorable situation will last, what consequences it will have, and what sharp or gradual start production will have after stabilization. It may well be prepared in advance for different scenarios. Damage can only be eliminated by responding quickly to the opportunity.

Timely response to changes in customer requirements in the form of prompt adjustment of the production plan is clearly a competitive advantage that will ensure customer satisfaction and, thanks to it, the establishment of long-term cooperation. However, it is not always an increase in production based on the customer's order. There may be a decrease for various reasons. In that case, it is necessary to react again sane and, if possible, include other types of products in production that are the content of another order. The published study deals with the analysis of the current state of production and subsequent proposals for increasing productivity and economic efficiency to improve the internal conditions of the factory, using a software tool from previous workplace research for team planning of production and logistics systems in the factory.

When balancing workplaces resp. lines is often a problem that balancing is not considered comprehensively. The task of redistributing activities resp. their time duration so that they fit into the beat may seem easier than it really is. The key is the logical sequence of successive activities in order to maintain a smooth flow of production without the need to wait for any of the activities and often also the inability to separate certain activities due to, for example, endangering the quality of the finished product. Not to mention product mixes, thanks to which the balancing of lines or workplaces proceeds to a new level. 


\section{Basic premises for developing innovation}

As we know, innovation, disruptive technologies or new approaches do not just happen. They always seem to spring out of the so-called mycelium. This mycelium is represented by the so-called space and potential for innovation to emerge. The result is a basic model that is represented by three organizations: universities, factories and R\&D and innovative organizations. This basic model can be supplemented by talented individuals and experts, research centers, incubators, clusters or public authorities and local governments, e.g., regional development agencies or regional councils. Creating such a model and cooperation will profit all the stakeholders. Collaboration between universities and industry is currently seen as a crucial medium to improve innovation throughout the economy by means of knowledge and technology transfer (Weerasinghe \& Dedunu, 2021), (Alves, Quelhas, da Silva, \& Lameira, 2015). Such models will ultimately transform traditional industrial economies into economies based on the creation and financial appreciation of knowledge and creativity (Balog, et al., 2013), (Hudakova, et al., 2018).

A common problem of SMEs in the field of innovation is the so-called self-containment and noninvolvement in partnerships. Finance can also seem to play a role. However, factories do not have to implement only groundbreaking and major innovations. They can take small steps and use the capacities of other sectors and partners. This will save money, which they can invest, e.g., into implementing disruptive technologies fit for their circumstances. This will result in improved internal factory conditions, improved productivity and in attracting customers. It works without problems in large factories, and many are a great inspiration to all of us.

\section{Development and use of the creative economy elements}

Clusters and collaboration implementing health promotion initiatives are composed of factories and organizations that collaborate with one another (Ainsworth \& Chesley, 2020). Today, the boundaries between different industries and sectors are blurring, and everything is interconnected. Different factories and associations also cooperate with each other. As recently as 21 years ago, it was inconceivable to have the Internet at home. Creativity is used today in every area of our lives. The cultural and creative economy is a natural environment for innovative ideas, development and appreciation of creative potential. Creativity is the key to innovative and interdisciplinary responses to global and local challenges - whether economic or social. In recent years, the concept of an innovative economy has been intensively pondered at various conferences, discussions and forums. However, creativity and its contribution to economic growth have so far not received sufficient attention. It is necessary to realize that creativity is a source of innovation, non-traditional solutions and concepts. If we look back, if it were not for creative and innovative people and their inventions, our society would remain without progress. Progression must also be ensured, from Creativity and human potential Innovation in factories - Technical progress in factories - Productivity growth in factories to Economic growth in factories. Only such perception of creativity can represent a practically feasible way of overcoming the crises constantly threatening today's global society (Balog, et al., 2015), (Dvorsky, et al., 2020).

Creativity has a complex character in many areas (Kacerauskas, 2020). It must not be perceived only as an application of new knowledge but must also be perceived economically, environmentally, politically, and socially. Creative industry in mutual synergy with a knowledge-based economy creates conditions for a strong and sustainable creative economy. It is necessary to remove barriers in science and research, ensure appropriate protection of intellectual property, andead towards creativity (Vesela \& Klimova, 2014). Progression must be ensured from Creativity and human potential - Innovation in factories Technical progress in factories - Productivity growth in factories to Economic growth in factories. Only such a perception of creativity can represent a practically viable way to overcome the crises that today's global society is constantly threatened by. Creativity is a business phenomenon only successful if the primary idea can be transformed into a product or service that brings social benefits and, through its purposeful commercialization, values the capital invested in it.

A common problem of SMEs in creativity is the lack or non-utilization of creative people and human potential. Many SMEs do not focus on collecting implicit and explicit knowledge from workers. This constitutes a big problem. On the contrary, in large factories, such approach is a matter of course. Many SMEs are also suppliers to large factories. Therefore, it would be interesting for large factories with SMEs, universities, or other research organizations to create e.g., alliances, clusters, etc., and pass on 
different kinds of knowledge. In this way, the WIN-WIN strategy and the progress of the whole society can be achieved. With the development of economic globalization, research is expended gradually from a single factory dynamic capacity building to inter-factory cooperation to form unique dynamic capacity, enhancing the competitive advantage of factories (Zhao, Xu, \& Xu, 2021).

\section{Digitization in factories}

Digitization is a huge chance for small and medium-sized enterprises (SMEs). But here is a big problem in SMEs. They are not very fast, agile, and daring due to just one in four SMEs has invested in the latest and innovative technologies in recent years. It is too little; however, opportunities for SMEs are very well. But they do not provide a lot of information about the latest technologies. Many money is invested in buildings and new machines. The competitive and Industry 4.0 view is necessary to implement new technologies into SMEs quicker. SMEs must have an efficient strategy for digitization in their field. (arts, 2020).

\section{Implementation of innovative ideas in practice - case study}

Modern planning and design of production systems, addressing complex parametric models with more than one monitored indicator, require an inextricable connection of the methods used for planning and design with computer technology. During previous research at the Department of Industrial Engineering in Žilina (KPI), a part of the software module for production design was created (layout creation, operations planning and workplace balancing) (Matys, et al., 2020). Using this technology, it is possible to build a three-dimensional (digital) production layout model, together with the data structure of the production process (production data model). The digital model of the production and the production process is then analyzed, and the possibilities of increasing its efficiency are explored. KPI also works closely with the Digital Enterprise department at CEIT, a.s. (Gabajová, et al., 2019).

\section{Current state analysis}

Analyzing the current state, we focused on the assembly process of one production line manufacturing reciprocating compressors. In the assembly process, the task of the workers is to complete, test, and pack the given compressor type. The basic part of the product, which gradually sucks in the gas (ambient air) during the movement of the piston in the cylinder, compresses and pushes it out, is produced inhouse. The patented solution without oil technology is what ensures the demand. Thanks to a suitable combination of materials, the technology works without the need for oil lubrication, i.e., the air that comes out is clean, without oil vapors and odors.

The basic problem in compiling the current state analysis of the assembly process was the lack of data. The data stored in the electronic form represented only a digital model of the assembled product, the assembled parts and components, the assembly breakdown in the form of a BOM and a 2D production layout model. The problem was that planning in the factory stemmed from the experience and knowledge of the executive manager who, after many years, perfectly masters the assembly process and passes on his experience and knowledge to new employees. To map the current production state, it was necessary to analyze the entire assembly process, preparatory operations included. The analyzed data were processed in a complex software titled Ceit Table. We used video sequences and the MTM (Methods-Time Measurement) methodology to evaluate the duration of assembly operations. In the current state (layout and processes), waste has been identified in the form of unnecessary operator transitions and multiple moving of the assembly, searching for the necessary tools at the workplace, or for the assembly process input parts (Onofrejová, et al., 2019), (Sásik, et al., 2014).

To determine the size of inter-operational conveyance, it was necessary to analyze the packaging of the purchased input components as well as components produced in-house. In the next step, it was necessary to define the technological sequence of assembly of individual components to ensure the product's assembly. Based on the sequence of individual steps, it was possible to delimit the assembly groups and thus create a precondition for introducing a production line layout. The current arrangement of the production layout has the form of a workshop, with elements of batch production. The assembly process consisted of 23 basic operations. Fig. 1 shows the duration of individual operations and the categories represented as a percentage according to the above classification, the visualization is abridged (selection $1-12$ is shown) for better readability.

Fig. 1 shows that a significant number of activities in the assembly process does not add value. This category included activities such as moving from a table to a rack or the parts pallet, searching for tools 
or a part to be assembled, worker's bending, and repeating his movements. From the total original time of $4865.35 \mathrm{sec}$. necessary for assembling the product, the value-adding activities represented only $25.94 \%$, apparent waste accounted for $38.33 \%$, hidden (but necessary) waste $28.25 \%$ and the equipment times $7.48 \mathrm{sec}$.

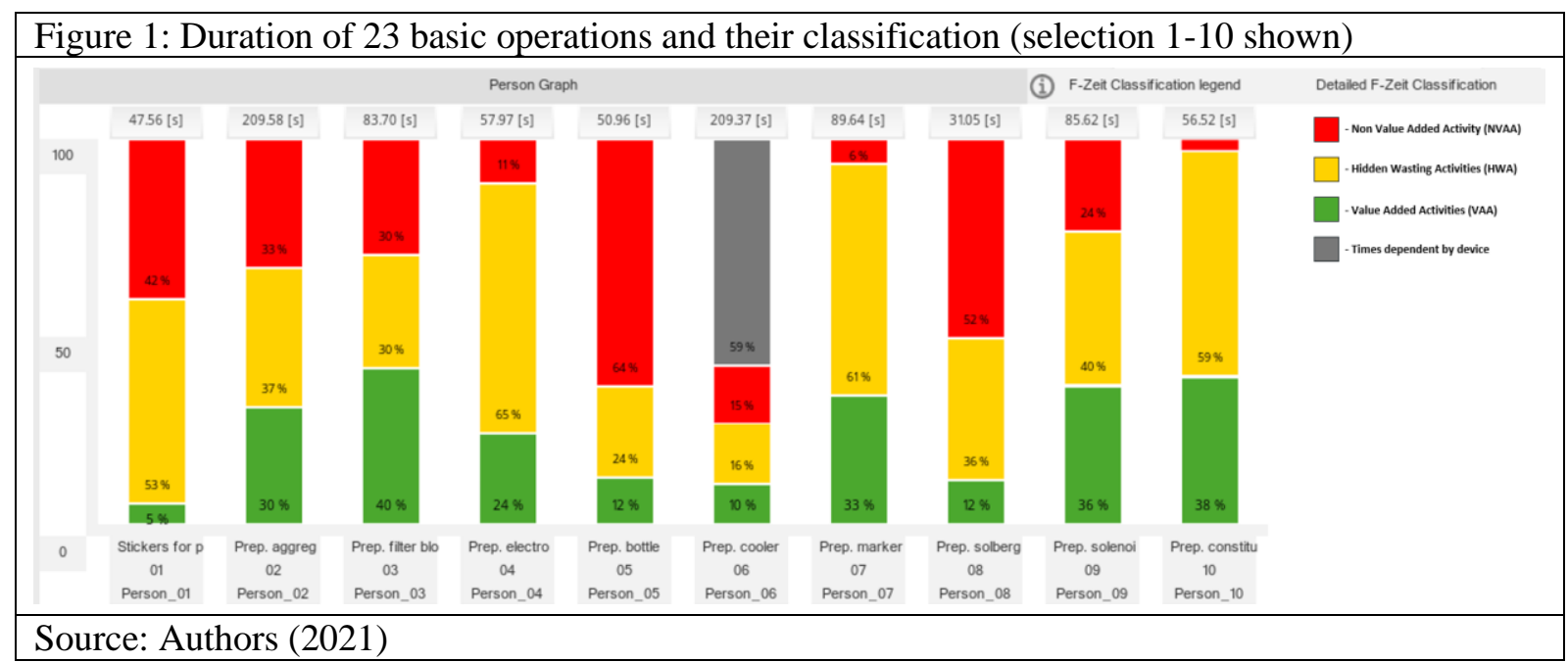

\section{Future state proposal}

Our proposal consisted of eliminating the identified forms of waste with the help of gradual implementation of lean manufacturing elements using the innovative and creative potential of the implementation team and the factory's implementation team. A rationally designed workplace is the basic constituent of lean production (Grznár, et al., 2020), (Viktor, et al., 2019). How well a workplace is designed depends on the movements that workers have to perform on a daily basis. Time consumption, performance standards, production capacity and other production indicators are then derived from workplace movements. The goal of lean management and subsequent production scheduling is to synchronize material flows. As mentioned in the previous section, flow synchronization is the basis for streamlining the production and assembly processes in the factory with the aim of making the production leaner. Experience from the past has been applied to this project, too. We implemented the synchronization of flows in three areas: a smooth flow creation, application of the pull method of production control, and the scheduling of production to achieve the smallest batches possible.

In the first step, we tried to combine the processes to form one continuous flow. One of the methods used to create a smooth flow is the OPF (One Piece Flow) concept (Krajčovič et al., 2012), (Pekarčíková, et al., 2020). At the factory, we applied our steps customized to transform the production into OPF:

1. Putting together a project team consisting of the production associates, the planning department, and the consulting partners in this project. The second part was defining the key product groups (representatives), using the P-Q analysis.

2. Selection of key processes for OPF implementation. Based on the constraints in terms of assembly and sequence of the assembly process individual steps, the project team established the operations that would be carried out on the assembly line.

3. Preparation and collection of data needed to smooth the assembly. Following the data preparation and collection, it was necessary to create a "Yamazumi chart". Fig. 2 represents a design based on the gradual analysis and waste elimination resulting from the current production layout. Basic operations (Fig. 1) were divided into smaller assembly operations; these were gradually assigned to units for individual work positions (P_01 to 06) and tacts (E_1 to 6).

4. Mapping the line conditions (waste identification Fig. 3). Using the software tool functions, we imported MTM tasks with the classification suitable for individual assembly cycles.

5. Implementation of the assembly line smoothing process. At this point in the project, the process as a whole was described, job positions and their tasks were identified and described (working standard).

6. Waste elimination in individual processes. Goals definition: elimination of extra work caused by repairs, defective production, losses caused by gluing technology Fig. 3 (P_02 and P_06). 


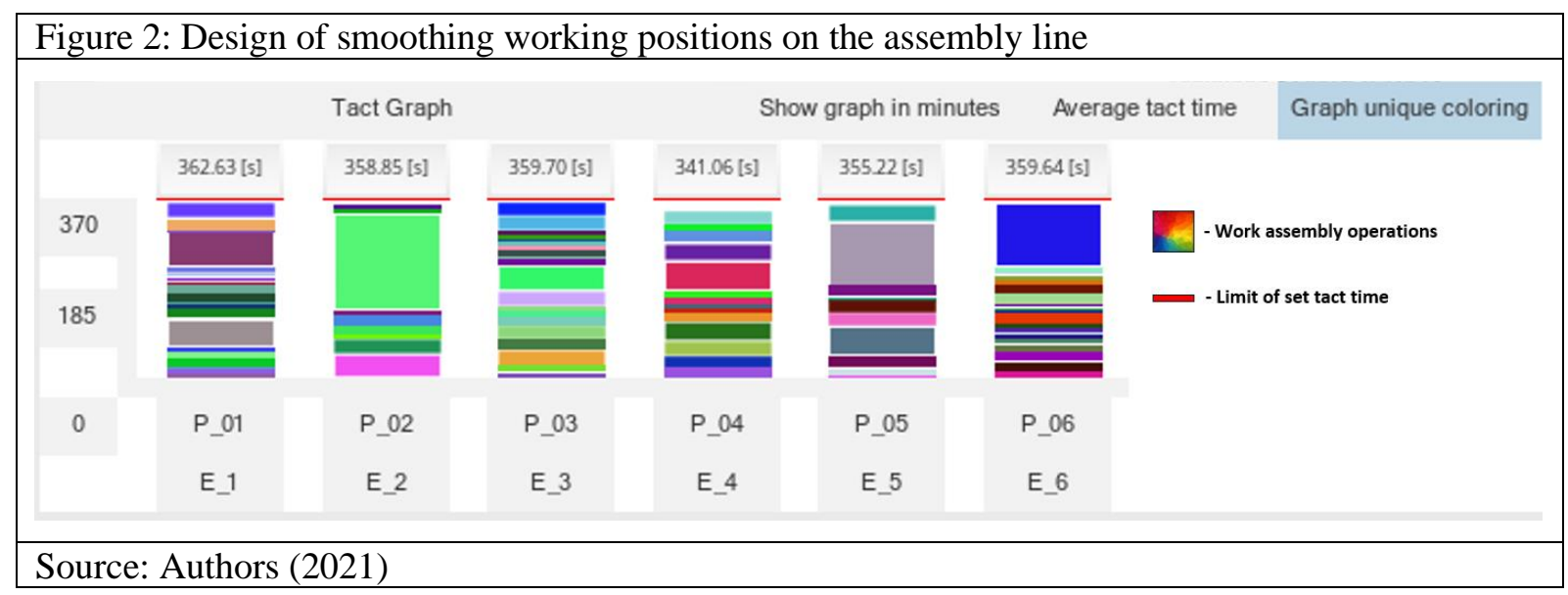

\begin{tabular}{|c|c|c|c|c|c|c|c|}
\hline & \multicolumn{6}{|c|}{ Person Graph } & -Zeit Classification \\
\hline & $99.35[\%]$ & $98.32[\%]$ & $98.55[\%]$ & $93.44[\%]$ & $97.32[\%]$ & $98.53[\%]$ & \\
\hline \multirow[t]{2}{*}{100} & & $27 \%$ & & & & & - Non Value Added Activity (NVAA) \\
\hline & $54 \%$ & $26 \%$ & $56 \%$ & $43 \%$ & $57 \%$ & $45 \%$ & - Hidden Wasting Activities (HWA) \\
\hline \multirow[t]{2}{*}{50} & & & & & & $30 \%$ & - Value Added Activities (VAA) \\
\hline & $45 \%$ & $45 \%$ & $43 \%$ & $50 \%$ & $40 \%$ & $22 \%$ & - Times dependent by device \\
\hline 0 & P_01 & P_02 & P_03 & P_04 & P_05 & P_06 & \\
\hline
\end{tabular}

7. Proposal of a new assembly line design (elimination of waste from point 6). Identification and creation of job descriptions (setting a work standard).

8. Repeated analysis and waste elimination. The green bars $\mathrm{P} \_01$ to 06 represent the original operations (option no. 1) of the assembly process without modification of the assembly technology (Fig. 4). The purple bars represent option no. 2, where waste in the form of a lengthy technology for gluing foams (device soundproofing) by manual glue application (choice of self-adhesive foams) has been eliminated. The last column (option no. 3) represents the selection of certain operations, these would be performed outside the line tact, and the assembled parts resulting therefrom would be delivered to the line as inputs.

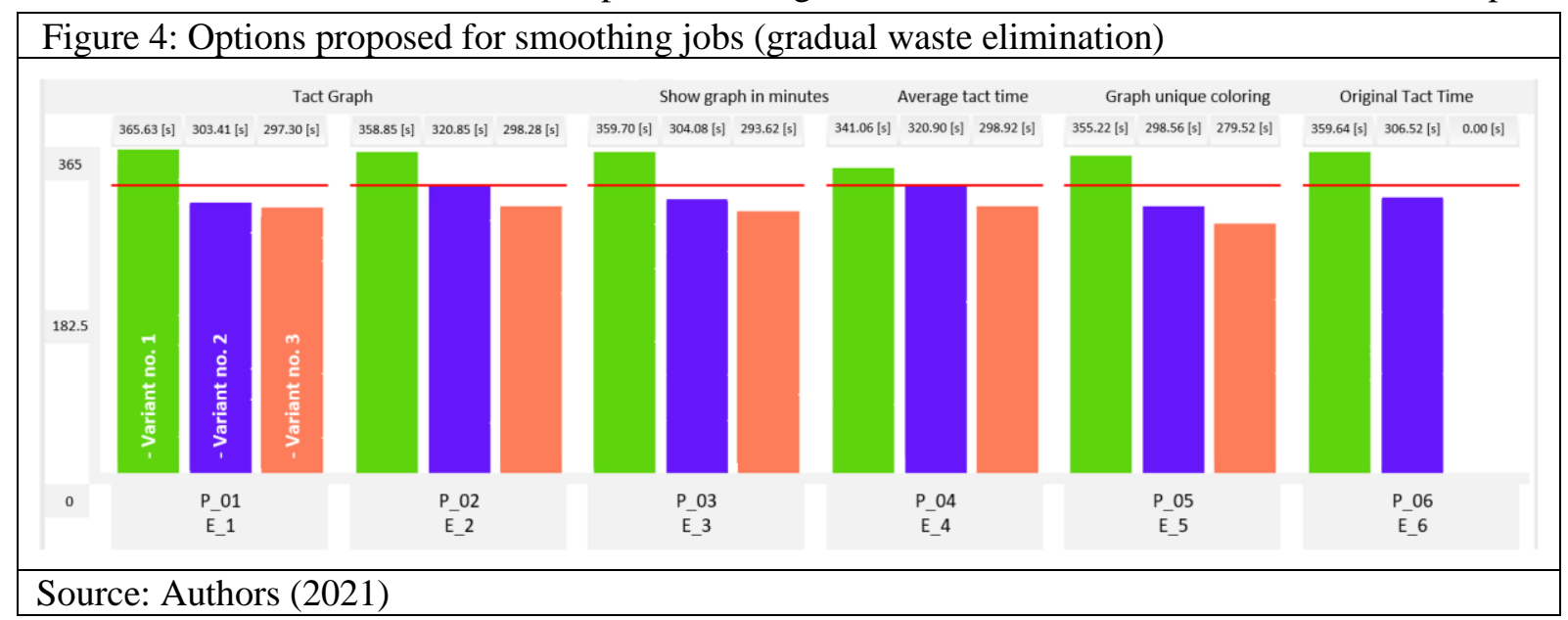

9. Creation an "I-shaped" assembly line with new staffing. Fig. 5 shows a new assembly line concept following the implementation of modifications (option no. 3).

10. Reducing the staffing of the assembly line with further improvements (the continuous improvement process). The process audit is scheduled half a year after introducing the proposals, the second one after a year. 
The great benefit is that the software is able to provide information and feedback on the impact of the proposed changes in production layout on the capacity needs of the production staff. The case study proved that with the help of the software, it is possible to reveal significant potential for rationalization of the already existing production systems.

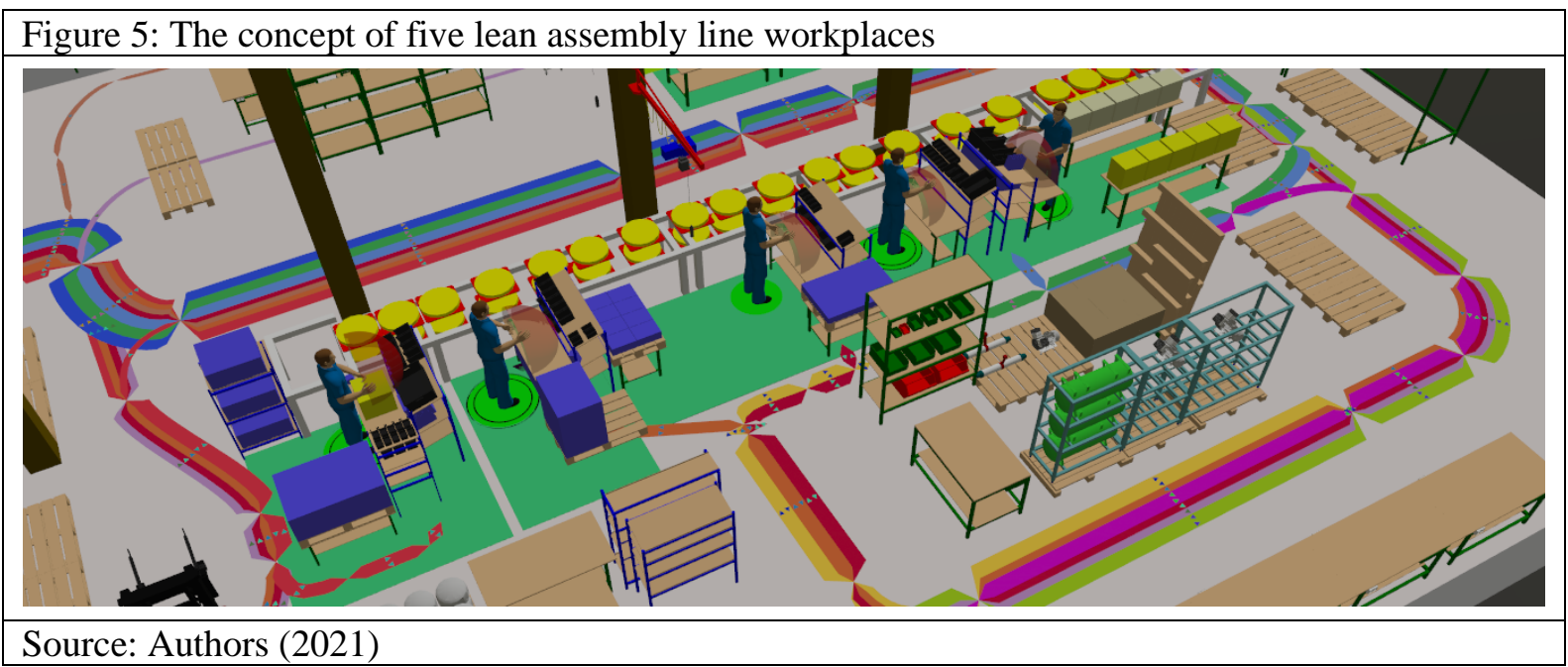

\section{Conclusion}

In the introductory sections of our paper, we pointed out the areas of innovation, creativity and digitization, and the need for cooperation between universities, factories and R\&D and organizations (Zolochevskaya, et al., 2019). In the second part of the paper, we introduced our case study from a real factory. We applied all the already mentioned areas in the case study described. After presenting the results, the factory decided to implement the Option no. 3 (Table 1) with the line arrangement. There were many benefits: the plant increased production levels by $80 \%$ relatively quickly, without major investments. Staffing and intralogistics have been improved, failures have been reduced by $30 \%$, and the loss-making activities have been eliminated. The introduction of partial process digitization, especially in removing paper form and expanding or introducing tablets, smartphones, monitors, reduced the time required for the production design and layout and, last but not least, reduced costs. The rationalization team recommended that the factory develop the creative potential of all factory employees at regular weekly and monthly meetings through a variety of special training, coaching, games, and methods for finding waste in the processes.

\begin{tabular}{|c|c|c|r|c|}
\hline \multicolumn{2}{|c|}{ Table 1: Comparison of the results of the options proposed versus the current state } \\
\hline Options & $\begin{array}{c}\text { Tact } \\
\text { [sec] }\end{array}$ & $\begin{array}{c}\text { Production lead } \\
\text { time [sec] }\end{array}$ & $\begin{array}{c}\text { Production } \\
\text { [pcs / shift] }\end{array}$ & $\begin{array}{c}\text { Total number } \\
\text { of operators }\end{array}$ \\
\hline Current state & - & 4865.35 & 50.00 & 12 (assembly processes) \\
\hline Option no. 1 & 360.00 & 2160.00 & 75.00 & 6 (line) +6 (pre-assembly) \\
\hline Option no. 2 & 321.00 & 1926.00 & 84.00 & 6 (line) +5 (pre-assembly) \\
\hline Option no. 3 & 300.00 & 1500.00 & 90.00 & 5 (line) +6 (pre-assembly) \\
\hline
\end{tabular}

Source: Authors (2021)

The newly designed Assembly Line will be operated by a total of 5 workers and 6 workers will be needed for pre-assembly operations. The saving of one worker compared to the current state is based on the implementation of a new technology for gluing soundproofing foams. This improvement is based on regular meetings of both project teams and the search for solutions at innovation-creative workshops. The implementation resulted in the reduced time required to prepare these parts for the assembly process. Focus on SMEs is also the European Commission's priority. The European Commission has developed a strategy for sustainable and digital Europe. This strategy aims to help all SMEs, regardless of sectors, start-ups or traditional crafts. Many SMEs have difficulty choosing the right digital business strategy. They often have trouble using large data repositories. These repositories are most commonly available for large companies. SMEs also avoid implementing new innovative and disruptive technologies. Therefore, SMEs will be supported by up to 240 Digital Innovation Hubs (DIH) in individual parts of the European Union. (Commission_2, 2021). 


\section{Acknowledgements}

This work was supported by the Slovak Research and Development Agency under contract No. APVV16-0488.

\section{References}

Ainsworth, D., \& Chesley, J. (2020). Built to Collaborate? Organization Design and Coalition Success. Health Promotion Practice, 654-664.

Alves, A., Quelhas, O., da Silva, M., \& Lameira, V. (2015). On the role of university in the promotion of innovation: exploratory evidences from a university-industry cooperation experience in Brazil. International Journal of Innovation and Learning, 1-18.

arts. (2020, 7 28). arts. Retrieved from arts: https://arts.eu/insights/article/digitisation-in-medium-sized-businesses-first-stepsto-the-digital-transformation-for-smes/

Balog, M., Baláž, V., Brighton, D., Brzica, D., Hlinka, M., Jeck, T., . . Zajko, M. (2013, 2 5). Innovative Slovakia - starting points and challenges (in Slovak languague). Bratislava: Slovak Innovation and Energy Agency. Retrieved from SIEA_1: https://www.siea.sk/wp-

content/uploads/files/inovacie/publikacie/publikacia_Inovativne_Slovensko_vychodiska_a_vyzvy_SIEA.pdf

Balog, M., Rehák, Š., Šipikal, M., Szitásiová, V., Hlinka, M., Gavorová, S., \& Ivan, P. (2015). Possibilities of development of creative industry in Slovakia (in Slovak languague). Bratislava: Slovak Innovation and Energy Agency.

Borik, Š., Kmecová, A., Gašová, M., \& Martin, G. (2019). 42nd International conference on telecommunications and signal processing. Smart glove to measure a grip force of the workers (pp. 383-388). Budapest: IEEE.

Commission_1, E. (2021, 2 5). europa.eu. Retrieved from europa.eu: https://ec.europa.eu/growth/smes/sme-definition_sk Commission_2, E. (2021, 2 5). europa.eu. Retrieved from europa.eu: https://ec.europa.eu/growth/smes/sme-strategy_sk

Dvorsky, J., Belas, J., Novotna, I., Fero, M., \& Petrakova, Z. (2020). Quality of Business Environment of the SME: A Sectoral View. Communications - Scientific Letters of the University of Zilina, 163-172.

Frances, O., \& Palomar, M. (2019). Alicante science park as a sustainable innovation ecosystem through the promotion of university-industry cooperation, (pp. 9193-9196). Seville, Spain.

Gabajová, G., Furmannová, B., Medvecká, I., Grznár, P., Krajčovič, M., \& Furmann, R. (2019). Virtual Training Appôocation by Use of Augmented and Virtual Reality under University Technology Enhanced Learning in Slovakia. Sustainability, 1-16.

Grznár, P., Gregor, M., Krajčovič, M., Mozol, Š., Schickerle, M., Vavrík, V., . . B Bielik, T. (2020). Modeling and simulation of processes in a factory of the future. Applied sciences, 1-24.

Hudakova, M., Dvorsky, J., Buganova, K., \& Kozubikova, L. (2018). Analysis and Evaluation of Market and Financial Risks in Small and Medium-Sized Enterprises. Communications - Scientific Letters of the University of Zilina, 16-22.

Kacerauskas, T. (2020). Creative economy and the idea of the creative society. Transformation in business \& economics, 4352.

Kolomytseva, O., \& Pavlovska, A. (2020). The role of universities in the national innovation system. Baltic Journal of Economic Studies, 51-58.

Krajčovič, M., \& Plinta, D. (2012). A comprehensive approach to the inventory control system improvement. Management and production engineering review, 34-44.

Matys, M., Krajčovič, M., Gabajová, G., \& Wiecek, D. (2020). Software solution for 3D modelling and its application for education in industrial engineering. Zarzadzanie Przedsiębiorstwem. Enterprise Management, 10-20.

NARMSP. (2013, 2 5). MHSR. Retrieved from MHSR: https://www.mhsr.sk/uploads/files/eU2FzFAz.pdf

Onofrejová, D., Janeková, J., \& Šebo, J. (2019). Work Measurement Study to Increasing Productivity of Production Line. Acta Mechanica Slovaca, 50-55.

Pekarčíková, M., Trebuňa, P., Kliment, M., \& Rosocha, L. (2020). Material flow optimization through e-kanban system simulation. International Journal of Simulation Modelling, 243-254.

Qiu, R., Wang, Y., \& Chen, T. (2019). The Intertemporal Evolution Model of Enterprise R\&D Cooperative Network. Discrete Dynamics in Nature and Society.

Sásik, R., Haluška, M., Madaj, R., Gregor, M., \& Grznár, P. (2014). 55th INternational Conference of Machine Design Departments. Development of the assembly set for the logistic transport solution (pp. 75-79). Beroun: Prague: Technical University.

SBA. (2019, 2 5). monitoringmsp. Retrieved from monitoringmsp: http://monitoringmsp.sk/wpcontent/uploads/2020/07/MSP_v_cislach_2019.pdf

SBA. (2020, 2 5). monitoringmsp. Retrieved from monitoringmsp: http://monitoringmsp.sk/wpcontent/uploads/2020/08/Inova\%C4\%8Dn\%C3\%BD-potenci\%C3\%A11-MSP-na-Slovensku-1.pdf

Vesela, D., \& Klimova, K. (2014). Knowledge-based Economy vs. Creative Economy, (pp. 413-417). Barcelona, Spain.

Viktor, S., Yury, A., Nizova, L., \& Andreeva, E. (2019). Engineers as an object and subject of the development of innovative entrepreneurship at the mesoeconomic level. Journal of Applied Engineering Science, 251-255. 
Weerasinghe, I., \& Dedunu, H. (2021). Contribution of academics to university-industry knowledge exchange: A study of open innovation in Sri Lankan universities. Industry and Higher Education, 233-243.

Yang, J. (2018). Research on the choice of innovation management approaches and innovation performance in China. Journal of Advanced Oxidation Technologies.

Zhao, J., Xu, G., \& Xu, J. (2021). Research status quo and trend of research on dynamic capability based on the concept of ecological sustainability. Fresenius Environmental Bulletin, 521-531.

Zolochevskaya, E., Cherkasova, T., Arsenieva, V., \& Lozovova, L. (2019). CBU International Conference Website.

Containing factors of the Russian digital transformation at the transit stage from the formation of the digital economy to its development in the context of global trends (pp. 351-359). Prague: CBU Research Institute s.r.o. 